\title{
Depreciación de la plata, políticas públicas y desarrollo empresarial. Las pequeñas y medianas empresas mineras mexicanas de Pachuca y Real del Monte ${ }^{1}$
}

\author{
por \\ José Alfredo Uribe Salas \\ División de Estudios de Posgrado, FH/UMSNH \\ Rubén Darío Núñez Altamirano \\ Programa de Doctorado en Ciencias del Desarrollo Regional, ININEE/UMSNH
}

Se estudian las estrategias empresariales y la capacidad de las pequeñas y medianas empresas mineras que operaron en el Distrito de Real del Monte y Pachuca para obtener ventajas relativas tanto de la depreciación de la plata en los mercados internacionales como de las políticas públicas establecidas por los gobiernos mexicanos después de 1873 para paliar la caída del valor argentífero, en un contexto de monopolio minero-metalúrgico promovido por la Compañía de Minas Pachuca y Real del Monte. Se analiza cómo algunos pequeños y medianos empresarios locales dieron nuevos brios a la actividad minera y cómo se vieron beneficiados con la situación internacional. Se concluye que fueron las pequeñas y medianas empresas las que sustentaron el desarrollo productivo y empresarial que caracterizó el auge minero en la región de estudio durante periodo porfirista en México.

Palabras Clave: Pequeñas y medianas empresas mineras en el distrito de Pachuca y Real del Monte; depreciación de la plata; políticas públicas; desarrollo empresarial.

${ }^{1}$ La presente investigación contó con el apoyo del proyecto científico: Viajes científicos europeos en el Mundo Hispánico. De la visión armónica de la Naturaleza a las tesis evolucionistas, y forma pare de los resultados del mismo. Investigador principal Dr. Miguel Ángel Puig-Samper, Instituto de Historia-CCHS del Consejo Superior de Investigaciones Científicas (CSIC), Madrid (España), financiado por el Ministerio de Ciencia e Innovación (HAR201021333-C03-02). 
La depreciación de la plata ha sido identificada por la historiografía mexicana como uno de los obstáculos más importantes que enfrentó el sector minero que produjo dicho metal durante el porfiriato. Pero antes de la brutal caída de los precios internacionales, acaecida en la década de 1870, el Estado mexicano había puesto mucha atención a lo que estaba sucediendo en el mundo con la plata, el principal producto de exportación de la época. En la primera mitad del siglo XIX, cuando la mayoría de las economías con las que se tenía relaciones comerciales destituyeron el uso fiduciario del metal blanco, las políticas monetarias de México, tanto al interior como al exterior, pugnaron por mantener firme el sistema bimetalista (sustentado a nivel de circulación en las monedas plata). Durante algunas décadas más el gobierno logró su cometido y las empresas productoras del metal, por su parte, correspondieron al impulso de las políticas públicas con el incremento de sus inversiones y elevando sus niveles de extracción. Estas acciones, sin embargo, en muchos casos fueron frustradas por las repetidas complicaciones militares que enfrentó el país, así como por el desenvolvimiento de los mercados y las economías globales. No obstante fue en la consabida estabilidad política del porfirismo cuando las empresas mineras mejoraron su situación financiera y lograron sacar algunas ventajas de la devaluación de la plata.

\section{EL FENÓMENO DE LA DEPRECIACIÓN}

En el siglo de la conquista de América, el desarrollo comercial de Occidente confluyó en un mercado internacional que se sustentó en un amplio uso del sistema de intercambio monetarista. Este fenómeno permitió que el valor de la plata se mantuviera a la alza en años posteriores, gracias a su posición fiduciaria y de reserva de valor global'2.

Fue hasta los inicios del siglo XIX cuando el precio de dicho metal comenzó a descender. Inglaterra, que en el curso de las guerras napoleónicas había sacado las mayores ventajas del sistema monetario bimetalista, decidió tomar la batuta de la desmonetización del metal blanco al decretar en 1816 que la li-

${ }^{2}$ Los orígenes del uso de la moneda como medio de intercambio provienen de los años últimos de la cultura griega (siglo VI a. de C.), pero entonces la economía monetaria tuvo un desarrollo localista, tal como pasó en el periodo de la Edad Media cristiana. Esto se debió al excesivo atesoramiento de las monedas y a que la relación de valor entre el oro y la plata no estuvo regulada debido a lo ecléctico de las emisiones. Ya en el siglo XVI, el numerario constituyó el eje central de la riqueza y del intercambio comercial, mismo que empezó a ampliar sus dominios. La moneda de plata en particular fue notablemente utilizada en los mercados europeos y del Medio Oriente. Vilar, 1974: 34-35. 
bra esterlina sería acuñada solamente en oro. Evidentemente esta política no tuvo un eco inmediato en las economías europeas, pero sí redefinió, al paso del tiempo, la postura financiera de muchos países, debido a los fuertes nexos comerciales o coloniales que los unían con la entonces omnipotente Gran Bretaña.

Para contrarrestar el avance del monometalismo áureo, un grupo de países europeos creó la Unión Monetaria Latina con el fin de reforzar el sistema monetario «tradicional», fundamentado en el uso simultáneo de la plata y del oro $^{3}$. Dicho proyecto mantuvo estable el empleo de la plata en varios sistemas monetarios, incluido el mexicano, y coadyuvó a mejorar la apreciación de ese metal en los mercados internacionales.

Hacia 1860 la Unión Monetaria Latina había puesto todas sus esperanzas en el imperio de Maximiliano de Habsburgo en México, para que otorgase la plata suficiente para sostener el patrón dúo metálico, pero el deceso del gobernante y principalmente la guerra de Francia con Prusia ocurrida en 1870, ofuscó las pretensiones del organismo, mismo que fue disuelto ${ }^{4}$. A partir de entonces la relación de valor entre ambos metales habría de sufrir la mayor variación hasta entonces conocida ${ }^{5}$.

Asimismo la aprobación de Estados Unidos y Alemania para modificar sus sistemas monetarios en la década de 1870 , que poco después secundaron los gobiernos austriaco, italiano, francés, suizo, belga y escandinavo ${ }^{6}$, provocaron una perturbación mayor en los precios ${ }^{7}$. El resultado más evidente de esta dis-

3 Los países que formaron esta institución fueron Francia, Bélgica, Italia y Suiza. García Solórzano, 1963: 79.

4 Tras el derrocamiento de Napoleón III, Francia se enfrascó en conflictos internos que acabaron desintegrando al grupo pro bimetalista. De Lucio, 147 (México, 1987): 17-18.

5 Muchos factores coadyuvaron para que se gestara dicho cambio. La economía mundial sufrió un revés histórico en los años de 1873 y 1874 y existió también un importante incremento en la explotación de la plata, a la par de un decremento en los costos de producción gracias a los nuevos descubrimientos de yacimientos de mercurio y a ligeros perfeccionamientos en los sistemas de beneficio. Uribe Salas, 1999: 293-295.

${ }^{6}$ Estos países eran parte de la Unión Monetaria Latina, o la apoyaban, y así como habían sido reacios defensores del bimetalismo, lo desaparecieron al adoptar el patrón oro y desmonetizar sus piezas plata entre 1874 y 1879. Otros países de Europa que no pertenecían a la Unión, hicieron lo propio en los años mencionados. Quintana, 1931: 32-38.

7 Según el funcionario porfiriano Joaquín Casasús, el cambio monetario del imperio alemán fue la punta de lanza de la depreciación de la plata, por la gran cantidad de moneda de plata que envió al mercado. Después de la guerra franco-prusiana (1870-1871) Alemania desmonetizó sus caudales argénteos completamente, mientras que Estados Unidos, gracias a la ley Bland Act, continuó comprando plata pero no detuvo la depreciación. Casasús, 1886: 211-212, 244-245. Baumhauer et al., 1956: 539-542. Quintana, 1931: 33-43. 
gregación fue el exceso de moneda de plata que se ofertó en los mercados orientales, fenómeno que creó más desvalorización en dicho metal ${ }^{8}$.

Gráfica I. Fluctuaciones del VAlOR DE LA PLATA EN EL Siglo XIX (1864-1902)

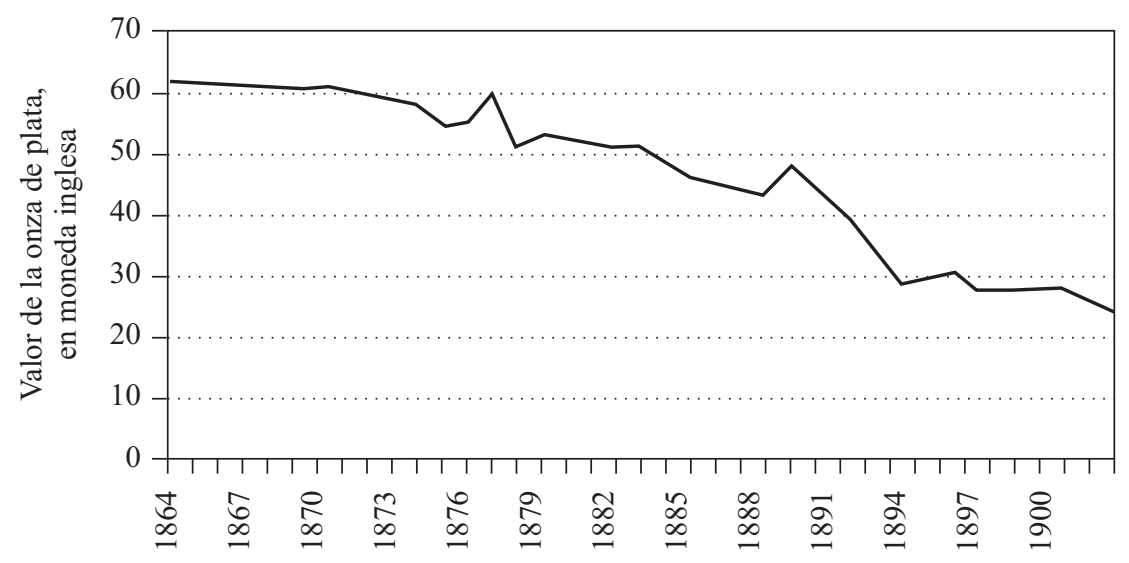

Años

Fuente: Limantour, 1909: 576.

En lo que respecta a la economía nacional, hubo crisis en el comercio de la plata debido a que la cuantiosa demanda china de moneda mexicana disminuyó paulatinamente por la caída de los precios y por la participación en el comercio de otros grandes productores de moneda de plata, como Estados Unidos y Australia ${ }^{9}$. En términos monetarios, la economía mexicana resintió verdaderamente la baja de la plata en $1875^{10}$, y desde entones existieron fuertes crisis económicas en el país asociadas con la depreciación mone$\operatorname{taria}^{11}$.

8 La importancia del mercado oriental llegó a ser tanta, que la demanda o sobreoferta de metal blanco existente en aquellas latitudes fue determinante en los precios de la plata a nivel mundial; Marx, Engels, vol. 30 (México, 1972): 53-57. Nava Oteo, 1974: 205.

9 McMaster, VIII/3 (México, 1959): pp. 391-393.

10 En 1875 el peso mexicano valía, con respecto del dólar, \$1,01; para 1903 la paridad era de \$2,38. Del Cueto, 1959: 9-11.

${ }^{11}$ La mayoría de ellas provocadas por crisis agrícolas, Mason Hart, 1997: 243-244. 


\section{LAS POLÍTICAS DE ESTADO EN TORNO A LA DEPRECIACIÓN}

Aunque desde la época colonial ya había existido depreciación en la moneda de plata, las ligeras variaciones monetarias que se presentaron a lo largo de los tres siglos de dominio español no preocuparon demasiado a las autoridades en la materia ${ }^{12}$. Fue en los gobiernos de Benito Juárez, Lerdo de Tejada y Porfirio Díaz cuando hubo un importante impulso a las políticas públicas para atender el problema de la devaluación de este metal. En 1876 los gobiernos locales productores del mismo prohibieron la exportación de plata en pasta, con la intención de disminuir la oferta en el mercado mundial y coadyuvar a la recuperación de los precios ${ }^{13}$. Años después, el Estado porfiriano previó que la única solución al problema era sostener y extender, a toda costa, el compromiso que la Unión Latina había estipulado años antes. Este acuerdo consistía en mantener la demanda del metal blanco, vigilar la paridad entre el oro y la plata mediante un fondo de reserva internacional - junto con la realización de convenios bilaterales-, y mantener el uso monetario de la plata en ciertos paí$\operatorname{ses}^{14}$. La disposición de los gobiernos en turno, favorable a la defensa del sistema monetario bimetalista, fue determinada por el crecimiento en las exportaciones de plata, que estimularon la economía mexicana.

Sin embargo, la perdurabilidad del sistema monetario mexicano afectó el poder adquisitivo por la inflación y las finanzas federales, al minimizar el ingreso público por derechos de importación. Por esta razón se empezaron a escuchar voces de quienes clamaban que eran mayores los problemas que traía consigo el sostenimiento del patrón plata, que los «beneficios» de mantener una moneda devaluada. Ante esta realidad, el gobierno de Manuel González reconoció en 1883, año de una fuerte depresión mercantil, que a pesar de que el equilibrio comercial de la nación se había sostenido con la exportación de moneda de plata, «la depreciación hacía cada vez más difícil esa estabilización» ${ }^{15}$.

Pero lejos de considerar la desaparición del sistema bimetalista, en el segundo periodo de gobierno de Porfirio Díaz se promulgó la Ley Minera de 1884, pensada como un contrapeso a la depreciación de la plata ${ }^{16}$. Las refor-

12 En la colonia el peso de plata sufrió una depreciación de 33\% con respecto del oro, pero esta devaluación se dio en poco más de 300 años. Torres Gaytán, 1990: 39.

13 Velasco Ávila et al., 1988: 298-299.

14 Ibidem: 300-301.

15 Secretaría de Fomento, 1886: 342.

16 En realidad la regulación de los impuestos realizada por el Estado porfiriano era descendiente directa de la modificación fiscal de Matías Romero establecida en 1869, durante el gobierno juarista, la cual se caracterizó por disminuir impuestos a la minería (que antes de las 
mas legislativas del nuevo código fueron creadas para aligerar los «excesivos» impuestos a la minería, así como para auxiliar y garantizar el trabajo de los propietarios de las minas de plata; pero también incidieron para que el alza de los cambios no afectara demasiado la producción de dicho metal ${ }^{17}$.

La protección del gobierno porfiriano a la minería de la plata se vio reforzada por la actividad diplomática de Matías Romero, quien había sido secretario de Hacienda en el gobierno de Benito Juárez y desempeñaba el mismo cargo en el gabinete de Díaz, antes de hacerse compadre y suegro de Porfirio Díaz. Este personaje fue un activo defensor del bimetalismo, y él mismo ideó en 1886 un proyecto de convención monetaria conjunto con Norteamérica, para «establecer el precio de la plata y aumentar el comercio de Estados Unidos con México». La propuesta incluía la creación de un gran mercado americano que, con la batuta de Estados Unidos, haría frente al dominio monetario europeo, integrando a Latinoamérica en un gran conglomerado monometalista de plata, que nunca se efectuó.

Un convenio de política exterior que sí fue operante se llevó a cabo con el gobierno chino para que se aceptase libremente la plata mexicana en las transacciones comerciales con nuestro país, aunque dicho tratado tuvo vida efímera ${ }^{18}$.

Por otro lado, y como complemento del código de 1884, el Congreso reformó la ley de impuestos a la minería en junio de 1887 , al disminuir a $2 \%$, el impuesto de extracción a metales preciosos (que anteriormente era de $3 \%$ ). También prohibió cualquier otro tipo de cargas fiscales, incluidas las que establecían los gobiernos estatales y que eran imposiciones pesadas para los empresarios mineros ${ }^{19}$.

Poco después, en 1891, México experimentó un fuerte déficit en el comercio exterior, lo cual aumentó la deuda externa del gobierno y fue un reflejo de la depreciación, que provocó una vez más una fuerte merma en los ingresos federales por concepto de aranceles ${ }^{20}$. Envuelto en esta difícil situación, el país

reformas de Romero se estimaban hasta en $25 \%$ con respecto del valor total de la producción de las minas), y en destituir los impuestos a la exportación de plata y oro, tanto en moneda como en pasta. Romero, 1992: 285-299.

17 Limantour, 1909: 602-603.

18 Romero, 1996: 135-162. Valdés Larowsky, vol. 9 (México, 1983): 16-17.

19 Bernstein, 1964: 19.

20 Fueron años difíciles para las importaciones, pues mientras en el año físcal de 1892-1893 el valor de éstas fue de 66.042.622 pesos, en el periodo de 1893-1894 — tiempos en los que aunque con menos intensidad continuó la baja en la plata-, disminuyó a 56.182 .942 pesos. Asimismo la exportación argéntea bajó de 47,8 millones a 35,1 millones en los años fiscales. Gurza, 1902: 9. 
enfrentó una grave crisis agrícola y comercial al año siguiente, la cual se hizo más intensa por una fuerte depreciación de la plata ocurrida ese mismo año ${ }^{21}$.

Desde mediados del siglo XIX la plata representó aproximadamente $77 \%$ del total de las exportaciones, y se utilizaba esta moneda en prácticamente todas las transacciones comerciales, por eso con esta importante crisis la economía mexicana presenció fuertes altibajos en su comercio interno ${ }^{22}$. Además, en la década de 1890 como nunca antes, los comerciantes comenzaron a comprar en mayores cantidades la plata en barras o en pasta. Los empresarios mineros por su parte, tratando de evitar los altos impuestos de amonedación, vendieron casi la totalidad de su producción a estos agentes, mientras que los exportadores mexicanos prescindieron de la amonedación y los impuestos que representaba.

Este hecho provocó que las casas regionales de moneda se enfrentaran a fuertes crisis, que en la mayoría de los casos dictaminaron su desaparición ${ }^{23}$. Esta cuestión preocupó al gobierno porfiriano porque el decremento en los envíos de plata a las casas de moneda significaba una fuerte caída en los impuestos de acuñación. Tratando de aliviar la escasa entrada de minerales a sus oficinas, el Estado redujo el impuesto de amonedación de la plata en marzo de 1897 , a sólo $1 \%$, y a $0,25 \%$ el de oro ${ }^{24}$.

Esta acción provocó un repunte en la fabricación de monedas e intentó fortalecer el comercio de pesos plata, pero era evidente que el antiguo y caro sistema de amonedación centralizado por el Estado había sido rebasado por las nuevas necesidades del mercado internacional. Como se observa en la gráfica II, el negocio de venta de plata en moneda decayó desde 1885. Esto se debió principalmente a la disminución de su uso en las transacciones comerciales en el mundo.

Es muy probable que esta situación fuera un signo de alarma para algunos sectores del gobierno, al representar un adelgazamiento del poder estatal y una renuncia a los impuestos y al arrendamiento de la emisión monetaria, ya que frecuentemente las casas de moneda se rentaban a particulares ${ }^{25}$.

21 Roeder, 1973, tomo II: 86, 87, 94. La crisis agrícola se debió a una disminución en la producción de maíz. Sánchez Díaz, 1988: 213.

22 Nava Oteo, 1980: 366.

23 Después de la gran depreciación de 1892, entre 1893 y 1895 siete casas de moneda cerraron sus puertas, éstas fueron las de Oaxaca, Oax.; Álamos, Son.; Chihuahua, Chih.; Durango, Dgo.; Guadalajara, Jal.; Hermosillo, Son.; y San Luis Potosí, S.L.P. Bátiz Vázquez, 1980: 181.

24 Limantour, 1904: p. 162. Nava Oteo, 1980: 339-343.

25 Ortiz Peralta, 1988: 131-153. 
Conjuntamente, y desde la época colonial, la población veía en las monedas circulantes una forma de inversión redituable, ya que regularmente se atesoraban y se sacaban a la venta cuando subía el precio de la plata. Este fenómeno provocaba un caos en la circulación monetaria interna que ya sufría de falta de circulante, y se agravaba con la aceptando «tlacos» y, nuevas denominaciones de origen bancario hacia finales del siglo XIX y comienzos del $\mathrm{XX}^{26}$.

GRÁFICA II. RETROCESO DE LAS EXPORTACIONES MEXICANAS DE MONEDA DE PLATA EN EL SIGLO XIX (1871-1901)

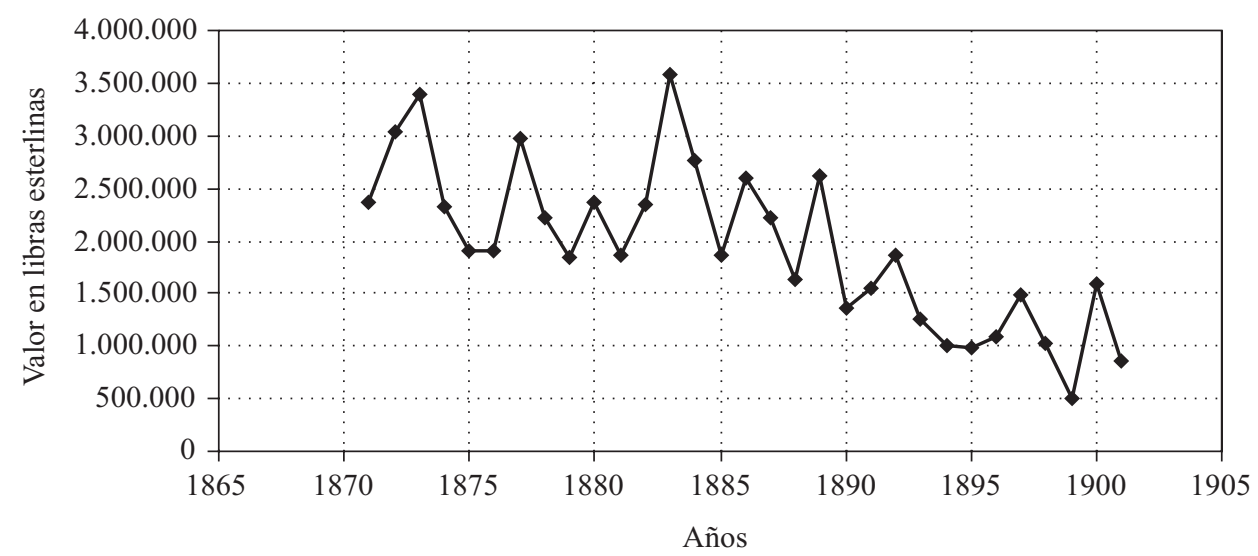

Fuente: Limantour, 1909: 576.

De todos modos, la mayor parte del gabinete porfiriano siguió recomendando no destituir el patrón de plata, entre otras razones para reforzar la utilización de las monedas de plata por medios legislativos, imponer el curso forzoso de las mismas e introducir el metal sobrante al sistema monetario. Para este efecto y opuestamente a lo que estaban realizando la mayoría de los sistemas monetarios internacionales, se suspendió la acuñación de monedas

26 Comerciantes, miembros del clero y gente común, guardaban sus monedas mientras seguían aceptando moneda en especie o «tlacos», es decir, desde pagarés emitidos por particulares hasta granos. La introducción de billetes a la circulación en forma masiva se dio sobre todo con la formación del Banco Nacional de México y del Banco Mercantil en 1882, y con la emisión de billetes que llevó a cabo el Nacional Monte de Piedad. Ludlow y Marichal, 1998. 
fraccionarias de cinco pesos hechas con oro y se cambiaron por monedas de plata $^{27}$.

No obstante, las políticas públicas darían un tremendo vuelco al iniciar el siglo XX. Al finalizar el siglo XIX factores de orden externo dieron un golpe de muerte al comercio monetario mexicano, sobre todo con la clausura de las casas de moneda de la India y la derogación de la Sherman Silver Purchase Act (legislación creada en Estados Unidos para permitir la compra de cuatro millones de onzas de plata al mes) ${ }^{28}$. A partir de entonces este sector del comercio exterior dependió casi exclusivamente del mercado chino. Pero como vimos anteriormente, la demanda oriental de moneda mexicana se debilitó en esta época debido a la saturación del mercado internacional de plata ${ }^{29}$.

A partir de entonces el gobierno buscó disminuir la enorme dependencia que tenían las finanzas públicas con la exportación argentífera. Por ello, las políticas de fomento comenzaron a desviarse de la minería de la plata hacia industrias como la agrícola, la textil, de comunicaciones y la minera misma, pero aquélla que combinara la explotación de oro y plata con la extracción de metales industriales ${ }^{30}$.

El fin de la política proteccionista al patrón monetario bimetálico pronto dio resultados, cuando se modificó dicho sistema en 1905 por el patrón oro. El resultado de esta decisión de Estado fue un gran conflicto entre quienes tenían intereses en la producción y el comercio de la plata, y el gobierno porfirista. A fin de cuentas este cambio en las políticas públicas fue más determinante para afectar a las empresas mineras que la depreciación, aunque sería el propio mercado internacional el que se encargaría de desbaratar las pretensiones monetarias gubernamentales, una vez que la plata comenzó a subir de precio y el oro se encareció con la crisis de 1907.

27 El proyecto de ley se emitió el 11 de diciembre de 1886, impedía la acuñación de monedas de oro de menos de 5 pesos, pero el curso forzoso de las monedas de plata no se llevó a cabo por el crecimiento regional de los bancos de emisión, quienes en billetes fraccionaban demasiado el valor del oro, lo cual, causaba mayor ganancia, pues no tenían el capital suficiente en plata para emitir moneda; Secretaría de Fomento, 1886, pp. 398-402.

28 Ley que se estableció en los Estados Unidos en 1890, después de la prohibición de acuñación argéntea; aunque el gobierno norteamericano compró cantidades importantes de plata a México, la ley Sherman ocasionó especulación por parte del Tesoro Federal yanqui y una mayor desconfianza pública en ese país para con las monedas de plata. García, 1970: 214.

29 McMaster, John, 1959: 391-393.

30 Uribe Salas, 2000: 318-319. 
AÑOS DE DEPRECIACIÓN Y DESARROLLO INDUSTRIAL EN LAS PEQUEÑAS Y MEDIANAS EMPRESAS DE PACHUCA Y REAL DEL MONTE

Los fuertes cambios que recién se estaban suscitando en los mercados internacionales con respecto del valor de la plata, no tuvieron un impacto directo en la mayoría de las empresas mineras del centro de México. Quienes producían plata no necesitaron implementar reformas radicales en sus minas y continuaron empleando los tradicionales métodos de extracción de mineral, mientras sus niveles productivos crecían progresivamente.

De hecho en Pachuca y Real del Monte la década de 1870 fue de auge en los denuncios de minas, y fue también cuando se conformaron las compañías mineras más exitosas durante el porfiriato. Ello no quiere decir que fueran tiempos idóneos para la inversión. La polaridad política que enfrentó el gobierno de Lerdo de Tejada en sus últimos meses de gobierno tuvo su punto cumbre a finales de 1876, cuando el movimiento tuxtepecano, comandado por Porfirio Díaz y particularmente en la región de Pachuca y Real del Monte por el General Rafael Cravioto, desconoció la administración lerdista. Precisamente en noviembre los sublevados, dirigidos por los coroneles Guillermo Pascoe y Pablo Durán, enfrentaron fuertes luchas contra el ejército federal, cerca de Pachuca, creando una vez más un fuerte ajetreo militar ${ }^{31}$.

Sin embargo, y a pesar del enrarecido clima político, los inversionistas locales emprendieron diversos proyectos para impulsar la extracción minera de la zona. En este sentido podemos destacar dos fenómenos que posibilitaron el desarrollo empresarial de las minas. El primero tiene que ver con el impulso directivo de mineros de la región que, mediante arrendamientos de minas y participaciones de capital, solucionaron problemas económicos y técnicos de las pequeñas y medianas empresas. Otro factor decisivo fueron los nexos que estos empresarios tenían con políticos e industriales de nivel nacional y que les permitieron crear redes económicas y políticas que coadyuvaron en el financiamiento de las explotaciones y en la creación de nuevas empresas.

Entre los casos destacados de entidades industriales que nacieron a la luz de la depreciación, tenemos a La Blanca y anexas, creada en 1876 por tres insignes residentes pachuqueños: el minero Tomás Mancera, el exdirectivo de la Compañia Real del Monte Francisco Rule y el inversionista José Pérez. Estos señores mantuvieron fuertes vínculos comerciales y mineros en la región, cuestión que les permitió explotar eficientemente las minas de La Blanca en

31 Manzano, 1927: 521. 
los años venideros ${ }^{32}$. Hacia finales del porfiriato, esta empresa contaba con una importante inversión en tecnología y pertenecían a ella un buen número de minas, ubicadas en su mayoría en los minerales de Pachuca y El Chico ${ }^{33}$.

Otra de las empresas más importantes tuvo su origen en el descubrimiento de la mina Santa Gertrudis, en $1874^{34}$. La gran riqueza aparente del filón de inmediato creó expectativas en Pachuca. Quienes lograron adquirirla fueron miembros de la familia Almaraz, tradicionalmente dedicados a la minería en dicha ciudad. A pesar del grandioso futuro que le auguraban a la mina, los Almaraz no tuvieron el capital suficiente para explotarla adecuadamente, aunque lograron mantenerla en amparo hasta 1879 . Pero fue entonces cuando la atinada dirección del ingeniero minero Bolland, que había llegado en los últimos años de vida de la Compañia de Aventureros de Real del Monte, produjo que la empresa aviadora de la mina Santa Gertrudis y Anexas, se convirtiera en la más productiva de la región, al extraerse semanalmente 1.576 toneladas de mineral. Esta cifra es muy ilustrativa de la importancia productiva de la empresa, ya que otras minas producían 210 toneladas en promedio en el mismo lapso $^{35}$.

La empresa San Rafael y Anexas fue fundada en Pachuca el 31 de agosto de 1874, con el denuncio de las minas Trinidad, San Rafael y Sorpresa. En esta época tales propiedades eran trabajadas con poco éxito por lo que pronto el accionista principal de la sociedad, el licenciado pachuqueño José María Barros, contrató diversos créditos que permitieron a la postre mejorar las actividades de la compañía, y así en pocos años la Cía. San Rafael se convirtió en la empresa mediana más importante del distrito de Pachuca ${ }^{36}$.

Para resumir el conteo de las pequeñas y medianas empresas pachuqueñas, en el cuadro siguiente podemos apreciar la creación de otras compañías en la década de 1870. Entre los socios que las formaron encontramos tanto a mineros locales, como políticos y empresarios notables. En este punto cabe destacar la acción promotora de los empresarios de la región con agentes económicos y políticos del centro del país y extranjeros avecinados en la región.

32 La empresa se dividió en 12.500 acciones y se le otorgó un capital social de 2.500 .000 pesos; González et al. 1911: 62. García, vol. XIX (México, 1925): 7-13.

33 En esta compañía, los vínculos financieros de sus directivos se remontaron hasta Guanajuato. Ibidem: 31 .

34 Ibidem: 56.

35 Las pequeñas compañías Fresnillo y Sacramento producían esta cantidad en 1882; Dahlgren, 1887: 212-213.

36 Southworth, 1905, tomo IX: 138. 
Tabla I. CReación de Compañías de Minas, en la Región de Pachuca y Real DEL MONTE (1875-1877)

\begin{tabular}{|c|c|c|c|c|}
\hline $\begin{array}{c}\text { Año de } \\
\text { denuncio }\end{array}$ & $\begin{array}{c}\text { Mina y/o } \\
\text { empresa }\end{array}$ & $\begin{array}{l}\text { Antiguos } \\
\text { Dueños }\end{array}$ & Socios & Ubicación \\
\hline $14 / 02 / 1875$ & Victoria & $\begin{array}{l}\text { Nicolás y Enrique } \\
\text { Grose y } \\
\text { Guillermo Barclay }\end{array}$ & Alfredo Snell y socios & Real del Monte \\
\hline$i^{/} / 1875$ & $\begin{array}{l}\text { San José de los } \\
\text { Doradores }\end{array}$ & & Santiago Ramírez y socios & Real del Monte \\
\hline $16 / 10 / 1875$ & $\begin{array}{l}\text { Cía. Aviadora } \\
\text { de la mina } \\
\text { Esperanza }\end{array}$ & & Pablo Téllez y socios & Omitlán \\
\hline $11 / 09 / 1876$ & Jesús María & & $\begin{array}{l}\text { Ignacio Symonds, Víctor } \\
\text { Pérez y socios }\end{array}$ & Real del Monte \\
\hline $7 / 07 / 1877$ & $\begin{array}{l}\text { San José y San } \\
\text { Nicolás }\end{array}$ & Vicente Dávalos & Isidoro Salcedo y socios & Pachuca \\
\hline $13 / 10 / 1877$ & La Trinidad & & Antonia y Piedad Islas & Pachuca \\
\hline $\begin{array}{l}27 / 10 / 1877 \\
\text { (emiten o } \\
\text { renuevan sus } \\
\text { certificados de } \\
\text { acciones) }\end{array}$ & $\begin{array}{l}\text { Jesús y San } \\
\text { Rafael y Anexas }\end{array}$ & & $\begin{array}{l}\text { G. Mancera Gregorio y } \\
\text { Pablo Martínez del Río, } \\
\text { Matías Romero, Manuel } \\
\text { F. Soto y socios }\end{array}$ & El Chico \\
\hline
\end{tabular}

Fuente: Periódico Oficial del Estado de Hidalgo, T. VIII, Núm. 1, 8 de enero de 1876: 8; Periódico Oficial del Estado de Hidalgo, T. IX, 7 de julio de 1877: 26; Periódico Oficial del Estado de Hidalgo, T. IX, Núm. 36, 27 de octubre de 1877: 8.

Los nombres de Santiago Ramírez y Matías Romero (el primero un importante ingeniero de minas que trabajó por años para la Secretaría de Fomento, y del segundo ya hemos reseñado su papel político-administrativo en los gobiernos liberales), denotan los nexos políticos que tuvieron algunos empresarios pachuqueños como Gabriel Mancera. Además la aportación accionaria de los hermanos Martínez del Río es un ejemplo de cómo los empresarios más importantes del México decimonónico fueron invitados a invertir en las minas de Pachuca, dando por resultado la creación de nuevas empresas ${ }^{37}$. Por su parte, Pablo Téllez, Alfredo Snell y el político Manuel F. Soto, fueron integrantes del círculo de inversionistas locales que siguieron interesándose en las minas de plata de la región.

37 El caso de los Martínez del Río, una de las familias con más abolengo, es notable. Estos empresarios tenían comercios, compañías de transportes, de textiles, de bienes inmuebles y, por supuesto, empresas mineras en buena parte del territorio mexicano, aunque para 1870 sus negocios estaban sufriendo graves pérdidas. Walter, 1991. 
En este momento habría que hacer un paréntesis para apuntar cuáles minas fueron trabajadas realmente. $\mathrm{Y}$ es que es común arribar a conclusiones sobre empresas que suponemos fueron productivas porque se encuentran en fuentes como los censos de la Secretaría de Fomento, cuando en realidad, en muchos casos, las propiedades mineras ahí citadas trabajaron poco o nada y únicamente se ampararon. Pachuca, por ejemplo, fue el distrito en el que más denuncios se registraron por esos años, pero también fue el municipio en el que existieron más amparos. Sin embargo, desde nuestra percepción, esta discusión de corte hermenéutico no invalida la aseveración de que las empresas de la plata vivieron un gran impulso durante el último tercio del siglo XIX. Aun con los amparos en la capital del estado de Hidalgo hubo un número importante de empresas que realmente trabajaron sus minas, algunas con muy buenos resultados y otras más apenas sobrellevando sus gastos, pero en ambos casos se continuó estimulando la inversión en la actividad minera.

Entre los casos más gráficos del repunte productivo de las empresas tenemos las compañías aviadoras de las minas Jacal, Corteza, Rosario, Valenciana, San Buenaventura y, sobre todo, San Pedro, Guactimotzin y Maravillas, que obtuvieron la mayor parte de la producción que el distrito de Pachuca presentó ante Hacienda. Las minas de las empresas Jacal, San Pedro y Guactimotzin habían sido trabajadas por la Cía. Pachuca y Real del Monte mediante contratos de avíos, durante la bonanza de la mina Rosario. Pero ante las dificultades económicas que atravesó dicha empresa en la década de 1870, se vendieron o regresaron los avíos después de 1872. Para entonces había acabado la bonanza de la mina Guactimotzin, que previamente había salvado de la bancarrota a la Cía. Real del Monte, durante una gran crisis ocurrida en 1868. Además, otros avíos que esta gran empresa tenía con pequeñas compañías, como La Luz y Xacal, terminaron ${ }^{38}$.

Contrariamente a lo que pudiera suponerse, el regreso de las administraciones aviadas a sus antiguos dueños no significó un retroceso en la conducción de las empresas medianas y pequeñas. A pesar del retiro del capital y de los bienes que prestaba la Real del Monte a dichas negociaciones, los trabajos que se llevaron a cabo en esta época redundaron en buenos resultados productivos.

En contraparte, la crisis económica que entonces estaba viviendo la Cía. Real del Monte, propició que los administradores de las minas arrendadas restringieran la explotación para pagar menos trabajadores ${ }^{39}$. Esta acción, lejos de contribuir a la mejora de la economía de la negociación en cuestión, aminora-

38 Ruiz de la Barrera, 1995: 132.

39 Ibidem: 230. 
ba las posibilidades de encontrar nuevas bonanzas y produjo malestar entre empleados y trabajadores, quienes en respuesta desarrollaron acciones de huelgas.

GrÁfica III. Producción de Las Minas del Distrito de PachuCA en 1875

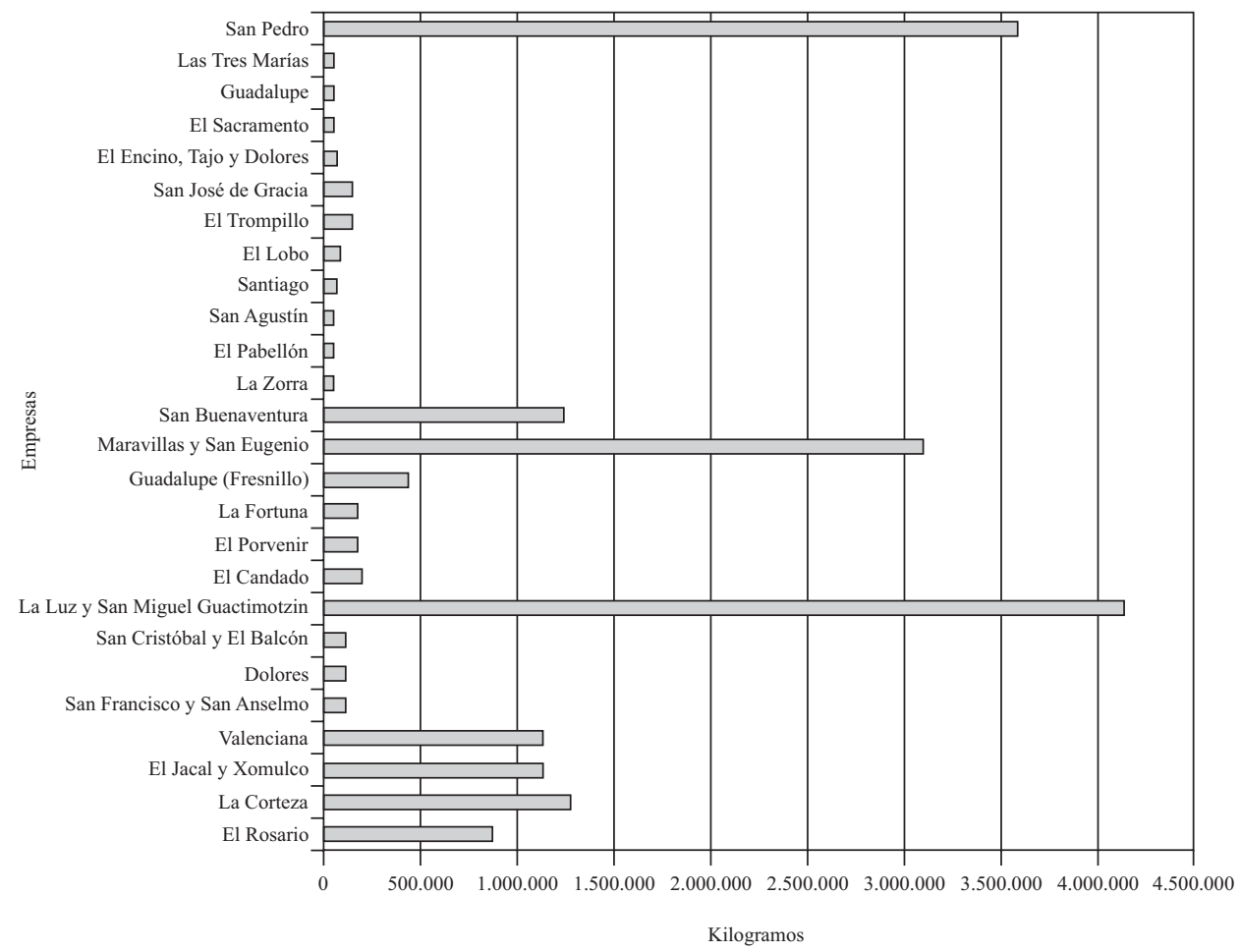

Fuente: Busto, 1880, T. II: 160-163.

La gráfica III nos da una idea de la producción emitida por las pequeñas y medianas empresas de Pachuca, que no fue poca, sobre todo tomando los casos de La Luz y Guactimotzin. Cabe destacar que algunas empresas expuestas en la gráfica, como las de Jacal y San Pedro, tuvieron importantes aportaciones por acciones de familiares de eminentes empresarios mineros, como los Escandón y los Béistegui, dueños de la Cía. Real del Monte ${ }^{40}$. De tal forma, en

40 Sobre todo de familiares cercanos, mayoritariamente hermanos; Urías y Meyer, 1987: 25-56 y $108-139$. 
las década de 1870 y 1880 , varias de las compañías medianas acrecentaron sus actividades de extracción y beneficio favorecidas por la integración de nuevos accionistas y capitales, situación que nos permite considerar a las medianas y pequeñas negociaciones mineras con características similares a las de grandes empresas ${ }^{41}$, sobre todo si comparamos sus números con los de otras compañías de sitios mineros distantes ${ }^{42}$.

Pero si analizamos el mismo fenómeno desde el punto de vista regional, observaremos que la enorme extensión física y productiva que tuvo la Compañia de Minas Pachuca y Real del Monte, sin cotejo en la comarca, nos permite definir cualquier otra empresa de la zona como mediana o pequeña, en razón de su producción, número de empleados, inventario físico y capital, siempre menor a la que llegó a ser la empresa minera más grande de México ${ }^{43}$.

Regresando al problema de las consecuencias de la crisis mundial del metal blanco en las empresas mineras, la historiografía unánimemente establece que la minería mexicana se debilitó más durante la década de 1880, puesto que muchas compañías mineras suspendieron operaciones debido principalmente a la depreciación y a una fuerte emigración de capitales externos ${ }^{44}$. Este suceso dio pie a una era de mayor escasez de recursos, en la que el capital local tuvo, cada vez más, una fuerte presencia en la minería regional ${ }^{45}$.

41 Tal es el caso de las empresas San Rafael y Maravillas y anexas, que incluso llegaron a cotizar en la bolsa con valoraciones muy altas de sus acciones. Véase: El progreso latino, tomo VI/1-24 (México, 1907).

42 Comparando los costos de las acciones de las empresas precedentes con los de la guanajuatense Cinco Señores, por ejemplo, encontraremos diferencias de entre 600 y 700 pesos. Idem.

43 Para una referencia más amplia: Herrera Canales, IV/8 (México, julio-diciembre 1989): 106-115.

44 Roeder, 1973: 87. Leal, 1972: 88. Capitales ingleses emigraron a fines del siglo XIX, no sólo debido a la crisis de la plata, también las colonias del país anglosajón necesitaron mayor atención económica, sin que esto significase la completa salida del capital inglés. Compañías como El Refugio Mining, El Oro Mining and Railway Co. Ltd, La Esperanza Mining Co., entre otras, además de las líneas férreas de capital inglés, continuaron operaciones en la geografía mexicana. D’Olwer, 1974: 1131.

45 Meyer Cosío, 1998: 27-30. Aunque la periodización de la etapa de dominio de inversores nacionales en la minería que propone este autor (1892-1898) corresponde al estado de Guanajuato, nos proporciona una idea de la situación minera nacional de entonces. Cabe destacar que el capital inglés regresó con fuerza al país desde 1886, y por esos años también las inversiones norteamericanas se empezaban a gestar, pero en el norte del país (véase en D’Olwer, 1965: 1015, y Berestein, 1964: 27-29) existen otras investigaciones que documentan la presencia nacional en años de continua presencia extranjera en la minería, y que concuerdan con la periodización guanajuatense. Uribe Salas, vol. I, 2002: 159-186. Miranda Arrieta, 1994: 68-72. 
En Pachuca y Real del Monte, por el contrario, el impulso que venía de la década de 1870 no se detuvo; continuaron creándose pequeñas y medianas empresas y las ya establecidas aumentaron sus niveles de extracción. Por ello, entre 1880 y los inicios del siglo XX, la actividad minera tuvo importante influencia en el crecimiento de la economía, de la infraestructura de comunicaciones y de los núcleos poblacionales de la zona ${ }^{46}$.

La Compañia de Maravillas incrementó notablemente su producción y se mantuvo en ascenso; mientras en 1875 producía poco más de tres toneladas de mineral, en 1886 extrajo 6.240 toneladas, y hacia 1900 obtuvo cifras mayores a las 20.000 toneladas en promedio. Esta empresa incrementó también el número de trabajadores empleados hasta mantener una media de poco más de 800 hombres $^{47}$. No obstante los minerales que extraía se vendían en el mismo patio de las minas, sin mayor beneficio, ya que no contaba con una planta de fundición y ensaye. Este sistema industrial evitaba costos de transacción pero a la vez eliminaba la posibilidad de obtener rendimientos mayores al ingresar al mercado fiduciario y de exportación.

La Blanca y Anexas, fue una de las empresas más preocupadas por invertir en tecnología a finales del siglo XIX. Contaba con mil operarios y además pagaba salarios relativamente altos, que iban de uno a tres pesos el jornal o destajo, según la capacidad técnica de los trabajadores ${ }^{48}$. Ciertamente el hecho de que la contratación de mano de obra fuera un problema para la mayoría de las compañías mineras, explica la existencia de estos salarios. Pero ello no exime la capacidad que tuvo esta compañía para ofrecer tales liquidaciones y mantener estable la producción, puesto que otras negociaciones casas suspendieron sus labores a causa de su incapacidad de pago ${ }^{49}$. Así, por las situaciones enunciadas, La Blanca y Anexas fue una empresa mediana que figuró como una de las más importantes de la escena minera pachuqueña.

Muchas de las minas que explotó la empresa San Rafael y Anexas formaron parte de la extensa veta Vizcaína, de la que se extrajeron grandes cantidades de mineral. Aunado a ello, la gran empresa Cía. Real del Monte mantuvo una estrecha relación con la San Rafael para explotar minas en conjunto, repartiéndose los costos de explotación y transacción, lo que proporcionó a la empresa mediana la posibilidad de mejorar sus finanzas. La empresa San Ra-

46 Herrera Canales, Ortiz Peralta, 1994: 30-31.

47 Busto, 1880: 160-163. Dahlgren, 1887: 213.

48 A lo largo de su vida productiva esta empresa compró motores Westinghouse, quebradoras Sandycroft, molinos tubulares Krupp, Mazos, etc., que eran vanguardia en tecnología minera; González et al., 1911: 63-64.

49 Romero Gil, 1998: 123. 
fael también tuvo la capacidad de controlar, por medio de avío, a las empresas Nuevo Cuauhtemoctzín, Demasías y Previsora ${ }^{50}$.

La Cía. San Rafael y Anexas fue una empresa que si bien no extendió demasiado el uso de tecnología moderna en sus minas (al acabar la era porfiriana continuaba usando mano de obra para desaguar algunos yacimientos) ${ }^{51}$, su directiva tuvo una capacidad de organización muy exitosa y supo hacer inversiones que la convirtieron en una de las más competitivas de la región.

Después de analizar estos notables ejemplos y citando la tesis de natalidad empresarial, es evidente que la región pachuqueña presentó condiciones favorables para la creación de empresas ${ }^{52}$. En este sentido Nava Oteo señaló, con respecto de la región central, que los estados de Hidalgo, Guanajuato y Jalisco fueron lugares en los que un amplio sector de los empresarios mineros tuvo considerables posibilidades de inversión, tanto en haciendas de beneficio como en minas ${ }^{53}$.

En Pachuca y Real del Monte la riqueza de las vetas, la capacidad empresarial de compañías como la Real del Monte, Santa Gertrudis y San Rafael, ciertas condiciones legislativas favorables ${ }^{54}$ y elementos externos al proceso productivo, dieron nuevos bríos a la minería lugareña (principalmente en la construcción de grandes líneas del ferrocarril que se instauraron desde 1872 y que terminaron de edificarse en 1883, abaratando los costos de transportación y permitiendo la explotación de minas antes no trabajadas) $)^{55}$. Evidentemente los denuncios de minas crecieron paulatinamente y la incidencia negativa que tuvo la depreciación de la plata en los mercados mundiales no fue tal en el interior de las empresas, donde más bien fue un aliciente para hacer más eficientes las técnicas de trabajo y reducir costos. De hecho la producción nacional del metal blanco sobrepasó con mucho los números de extracción efectuados antes de la depreciación ${ }^{56}$.

50 Ibidem: 130-159.

51 González et al., 1911: 76.

52 Véase Cerutti, 2002: 2-4.

53 Nava Oteo, 1974: 274-278.

54 «Código de Minería del estado de Hidalgo», Hidalgo, octubre de 1881, en Legislación Minera Mexicana, México, Consejo de Recursos no Renovables, vol. II, 1964: 4-32.

55 Véase, Ortega Morel, 2000: 85-159. Marichal, 1989: 160-174. Coatsworth, 1990: 180-182, 198-206.

56 Con ello no queremos expresar que el aumento de la producción de la plata tuviera un efecto directamente proporcional en la depreciación de la misma. Según Casasús no había una relación directa entre el incremento de existencia del metal y la baja del precio, pues la demanda, aunque reducida, se mantuvo. Y es que, ciertamente, los metales preciosos no pueden analizarse completamente con la teoría de la oferta-demanda (basada en la «soberanía del consumidor» en un sistema de mercado, la teoría de la oferta-demanda plantea que la demanda y el pre- 
Gráfica IV. Producción de Plata MEXicANa (1876-1893)

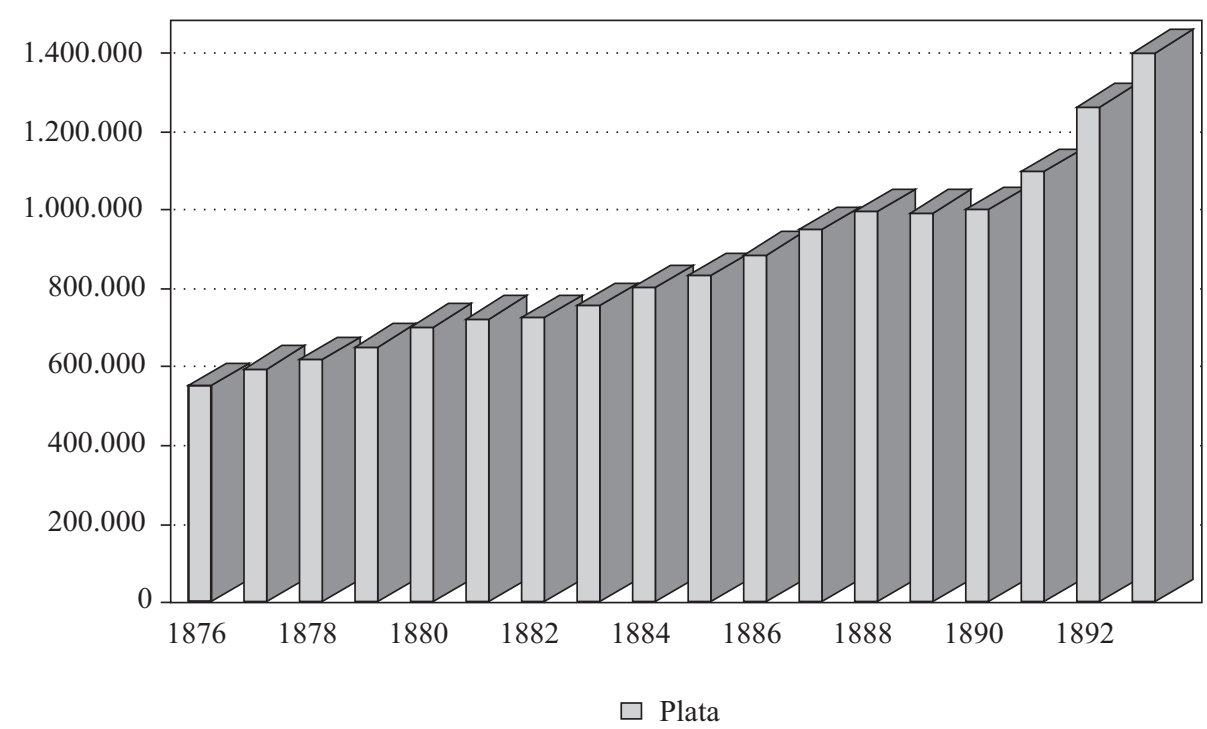

Fuente: Herrera Canales (México, julio-diciembre 1989): 122-123.

Contribuyó a ello el que la baja de la plata produjera, al menos hasta el decenio de 1890, un efecto favorable en el comercio de exportación del metal blanco, que encontró en los mercados europeos una ganancia de 20 a 30\% con respecto de los precios anteriores a $1873^{57}$, y el que los costos de producción se pagaran en plata y no en oro ${ }^{58}$. Fue decisivo también el hecho de que la libre acuñación permitida por el sistema monetario bimetalista mexicano se tradujera en un importante consumo de plata tanto para necesidades internas como para la exportación de moneda.

cio de las mercancías se basan en la preferencia de los consumidores, la oferta en los costos de las empresas, y ambas — oferta, demanda - son equilibradas por los precios de los bienes), pues aunque mercancías, los metales preciosos desempeñan oficio de moneda, con lo cual muchas veces no se insertan a los vaivenes de las transacciones mercantiles, ya que es continuo su atesoramiento, lo que mantiene su mercado aun en épocas de crisis en la cotización. Casasús, 1886: 215-216. Samuelson, Nordhaus, 1986: 71-87. Benetti, 1990: 11-23.

57 Casasús, 1886: 35.

58 Sariego, 1988: 52. 


\section{ESTRATEGIAS DEL EMPRESARIO LOCAL}

Es indudable que los mineros aprovecharon los progresos tecnológicos que trajeron las nuevas inversiones de empresas extranjeras como el ferrocarril, así como la política de disminución de impuestos del Estado porfiriano ${ }^{59}$. En muchos casos, el aumento de la producción argentífera se cifró en la entrada de empresas extranjeras que introdujeron más y mejores métodos de beneficio en lugares tradicionalmente productores de plata ${ }^{60}$. Pero en zonas como Pachuca y Real del Monte, que entraron tardíamente a los «beneficios» de la modernización tecnológica norteamericana, es imposible soslayar el papel del empresariado minero local y los medios que se utilizaron para incrementar la producción de plata.

En la región que nos ocupa, desde mediados del siglo XIX el empresario minero estaba entrelazado con residentes extranjeros, la mayoría de origen británico, que establecieron su residencia en la zona y que posteriormente adquirieron la nacionalidad mexicana. La unión de estos personajes con inversionistas nativos conformó un empresariado regional que supo sortear los embates del mercado internacional. Uno de los casos más representativos de este proceso fue el empresario Francisco Rule, originario de la región inglesa de Cornish, y del cual hemos reseñado ya su fuerte participación accionaria en las empresas Santa Ana, La Blanca y Santa Gertrudis. Estas empresas, junto con las compañías de Maravillas, Pabellón y Marcial Islas, promovieron el crecimiento productivo del distrito pachuqueño, donde se beneficiaban hacia 1892, un total de 2.100 toneladas de mineral semanalmente.

Las modificaciones técnicas fueron las actividades empresariales que más incidieron en la producción de plata. La combinación de métodos tradicionales y modernos en la explotación fue muy recurrida para realizar una organización certera del trabajo y para adaptar las técnicas y tecnologías mineras a las con-

59 En los inicios de la República mexicana los ingleses invirtieron 12.000 .000 de pesos en las minas (Ward, 1981: 355-356), inversión que incidió de sobremanera para que subieran las exportaciones de metales preciosos, de 1.324 .970 pesos en 1823 , a 13.591 .467 pesos en 1836 , y para que los mineros mexicanos que retomaron tales minas a mediados de siglo continuaran realizando altas producciones (Herrera Canales, 1977: 60-62). Con la oleada de inversiones externas en los años últimos del gobierno porfiriano, entre 1894 y 1901, crecieron los registros de minas explotadas, muchas de ellas subsidiarias de las grandes fundidoras extranjeras. En lugares como Aguascalientes ensayaron muchos más metales, de un millón de pesos en 1895 subieron a 25 millones en 1908; precisamente Aguascalientes y Monterrey beneficiaron $50 \%$ de la plata en 1908. Velasco Ávila et al., 1998: 174-175.

60 Como Real del Monte, Zacatecas, Guanajuato, El Oro y Tlalpujahua, entre otros. Uribe Salas, 1998: 95-108. 


\section{GráficA V. PROdUCCiÓN DE PLATA EN LAS EMPRESAS MEdiANAS Y PEQUEÑAS DE PACHUCA (1892)}

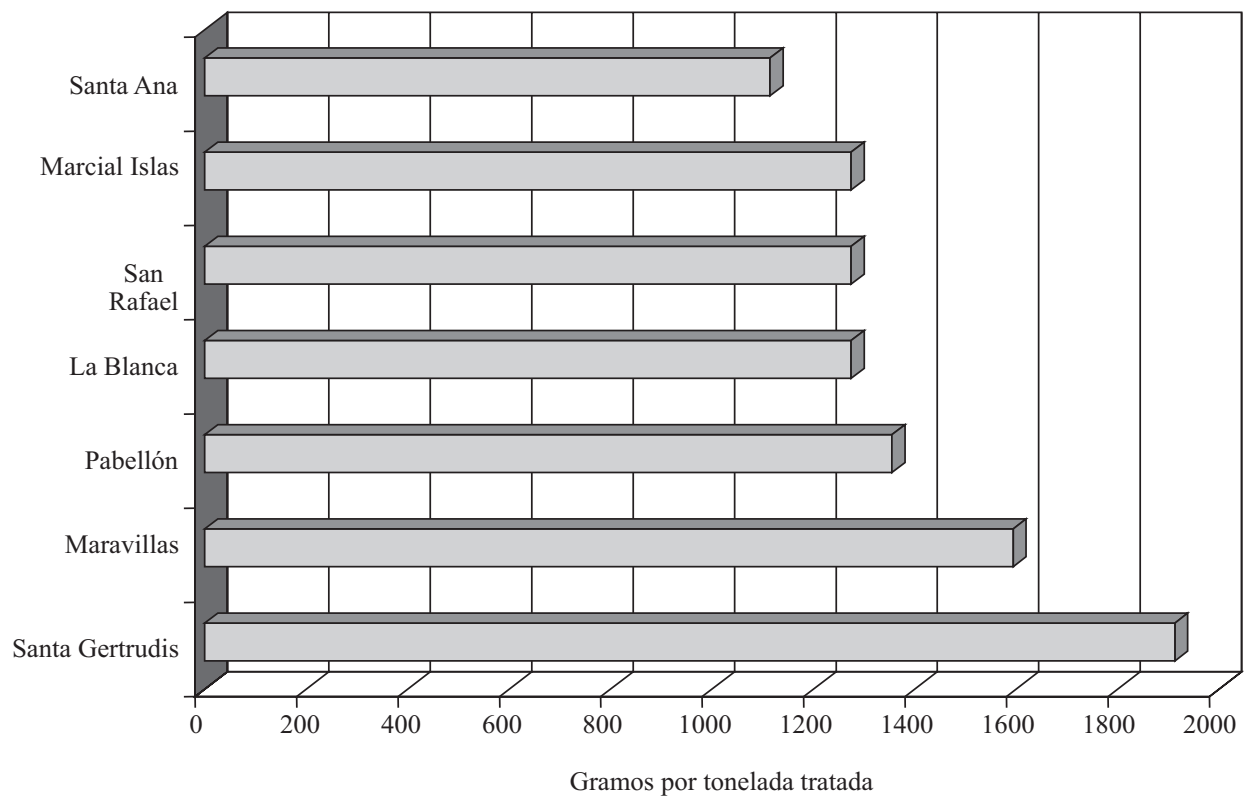

Fuente: Soto Oliver, 1985: 198-199.

diciones de infraestructura locales. En este sentido, tanto en la empresa más grande - la Real del Monte - como en la mediana San Rafael, se utilizaron conjuntamente el «antiguo» sistema de beneficio de patio y el «moderno» sistema de toneles, hasta inicios del siglo $\mathrm{XX}^{61}$.

Por otra parte, la Cía. Real del Monte incursionó en la producción de sal que tanto utilizaban los sistemas tradicionales ${ }^{62}$. Los mineros dueños de empresas medianas también tuvieron la capacidad de producir algunos de los insumos necesarios para la explotación minera, tal como sucedió entre las negociaciones Santa Ana y La Blanca y Anexas, que explotaron conjuntamente una mina de pólvora ${ }^{63}$. A la postre, los esfuerzos por mejorar las cuestiones técni-

61 Herrera Canales, IV/8 (México, julio-diciembre 1989): 103-105. González et al. 1911, p. 76.

62 Ortiz Peralta, núm. 14 (México, julio-diciembre 1991): 79.

63 Archivo Histórico de la Compañía de Minas Real del Monte (en adelante AHCMRM), Fondo Compañías Filiales, Sección Santa Ana, Serie Correspondencia, vol. 157, exp. 71. 
cas y de abasto no sólo mejoraron la situación de las empresas sino que también atrajeron mayores inversiones en la región ${ }^{64}$.

Otras modalidades que se llevaron a cabo para aminorar los efectos de la depreciación fueron la reducción de labores de exploración, de empleados y el otorgar a los trabajadores pagos en especie ${ }^{65}$.

A diferencia de lo que pasó en el norte del país, donde se pagaron salarios doblemente altos ${ }^{66}$, en el centro de México la continuidad en las explotaciones también dependió de la reducción en los montos por pagos de jornales. Y aunque los métodos productivos mexicanos tradicionales exigían un número mayor de trabajadores que aquéllos que utilizaban tecnología más avanzada, muchas empresas nacionales no gastaron demasiado en este rubro. Por ejemplo el trabajo de los pepenadores, esencial para extraer el mineral del «tepetate», era relativamente barato pues su salario no era mayor de 50 centavos diarios ${ }^{67}$. Sin embargo es muy arriesgado hacer generalizaciones al respecto, puesto que en las zonas más alejadas de las ciudades, como el caso del distrito El Chico - que estaba más retirado de Pachuca-, se pagaron salarios más altos. En este lugar el salario de los pepenadores iba de 75 centavos a 1,50 pesos, aunque debemos advertir que el pago de jornales elevados también fue parte de una estrategia empresarial para retener trabajadores, que escaseaban desde los años de la colonia.

Para muchas empresas un paliativo a las fluctuaciones de la plata en los mercados internacionales fue la explotación paralela de minería y agricultu$\mathrm{ra}^{68}$. La dualidad agrominera fue un binomio rentable, puesto que conforme la depreciación de la plata aumentaba la agricultura de exportación obtenía una prima considerable al recibir los pagos de estos productos en el exterior en oro, que al cambiarlo en el país por pesos plata duplicaba las ganancias. En la industria minera, la depreciación de la plata, según Matías Romero, alentó la producción de otros metales, pero la industria agroexportadora fue quizá el sector económico más beneficiado con la misma. Por otro lado las altas tasas de interés provocaron proteccionismo en el sector de las manufacturas, porque el pago en oro de las mercancías exteriores disminuía las importaciones ${ }^{69}$.

64 Véase Staples, 1994: 40-50, 200-203.

65 Flores Clair, núm. 13 (México, abril-junio 1986): 51, 65.

$66 \mathrm{Y}$ en Estados Unidos hasta 10 veces más; véase «Algunos puntos de comparación entre el funcionamiento de la minería en México y los Estados Unidos», Sariego et al., 1988: 388-390.

67 Salarios mantenidos gracias a la existencia de policía montada e incluso de militares que las entidades federativas ponían a disposición de los mineros, Guanajuato Consolidated Mining \& Milling Co. Sariego et al., 1988: 385-388.

68 Serrano, 1951: 28.

69 Estas palabras de Matías Romero son citadas en: Argudín Luna, XVII/67 y 68 (México, 1996): 174-176. 
Indudablemente las políticas de reducción de costos fueron responsables del crecimiento empresarial de la región. Pero también la inversión jugó un papel primordial en el crecimiento de las empresas mineras. En Pachuca, la compañía Santa Gertrudis gastaba en las dos minas que operaba - San Guillermo y San Francisco - un millón de pesos anualmente durante la década de 1880. Este presupuesto fue muy elevado, sobre todo si lo comparamos con los dispendios de la Pachuca y Real del Monte, que con sólo el doble de dinero mantenía sus 50 minas $^{70}$.

Cabe decir que así como la existencia de un gran número de empresas y de minas no necesariamente es sinónimo de un desarrollo industrial sustentable, el hecho de mantener una gran producción de minerales no significa la existencia de un número alto de empresas en producción. Es decir, con la combinación de una buena bonanza y una inversión decorosa, una o dos minas podían producir más que 20 en conjunto ${ }^{71}$. Precisamente éste fue el caso de Santa Gertrudis a inicios del siglo XX, porque en 1903 esta mina produjo 193.120.475 toneladas de mineral ${ }^{72}$. Con ello no queremos «derribar» la discusión precedente con respecto del auge empresarial de Pachuca y Real del Monte. Sólo queremos señalar que en el ámbito de una compañía minera, más que el servicio de maquila de minerales o la disminución planificada de los costos, la riqueza interna de una veta podía remediar súbitamente los problemas económicos de una empresa.

De igual manera la abundancia de mineral con altos contenidos de oro y plata incidió para que muchas empresas mineras continuaran siendo monoproductoras de estos metales y se esmeraran más en aumentar su producción que en diversificarla. Las empresas productoras de plata, grandes, medianas y pequeñas, hicieron más eficientes los mecanismos tradicionales de producción y beneficio, combinando en tales procesos el uso de tracción animal, maquinaria de energía hidráulica y de vapor $^{73}$. Además comenzaron a introducir otras innovaciones técnicas, como el uso de dinamita para perforar los tiros, de quebradoras de metal importadas, de pequeñas líneas férreas en los centros mineros, de maquinaria de combustión interna y eléctrica ${ }^{74}$.

Así las cosas, a finales del siglo XIX la gestión administrativa de los empresarios mineros se mostró mucho más preocupada por mejorar la economía de las empresas y por modernizar las actividades de producción.

70 Ruiz de la Barrera, 1995: 278.

71 La misma Rocío Ruiz, apunta que la PYRM obtenía 90\% de sus utilidades de escasas seis minas. Ibidem: 279.

72 Southworth, 1905: 135.

73 Herrera Canales y Rina Ortiz, 1994: 36.

74 Ibidem: 37. 
Antes del ingreso del capital norteamericano en la zona, las compañías mineras locales consideraron prioritario vender acciones en el exterior para obtener recursos foráneos. La Santa Gertrudis, en los años de 1893 a 1895, abrió sus puertas a accionistas de origen inglés que impulsaron los trabajos de la compañía y fueron un factor decisivo para mejorar la extracción; entonces producía 25.000 toneladas anuales de mineral y ocupaba más de mil trabajadores $^{75}$. Con tales números esta sociedad aviadora atrajo la atención de los mineros locales más importantes, como el director de la Cía. Real del Monte, José Landero y Cos, quien se convirtió en el presidente de la Cía. Santa Gertrudis. Este minero impulsó el exitoso rendimiento de las minas San Juan, Los Italianos, San Francisco, San Guillermo y San Miguel, y a través de su puesto mantuvo una intensa relación de avío y venta de minerales con la Real del Monte, hasta el año de 1906 ${ }^{76}$; aunque no permitió que la empresa Santa Gertrudis se convirtiera en filial de esta última, como lo hicieron entonces muchas compañías mineras ${ }^{77}$. Con la dirección de Landero y Cos, esta empresa también sufragó cantidades importantes para modernizar sus minas y trabajos de extracción acuífera.

El siguiente paso era mejorar la planta productiva de la compañía, y para ello se llegó a un arreglo con Gabriel Revilla para comprar la Hacienda de Beneficio Guadalupe, de la cual él mismo era socio. La transacción fue costosa, pues se organizó con un capital de 200.000 pesos, pero desde entonces las ganancias de la Santa Gertrudis se elevaron, ya que sólo en el año de 1903 se registraron utilidades de $417.038,95$ pesos $^{78}$.

La importancia productiva de la región pachuqueña a fines de siglo, expresada a través de la capacidad y el número de las haciendas de beneficio existentes, mucho debió a los movimientos empresariales que realizaron las compañías medianas para aminorar los costos de transacción, al construir o comprar sus propias instalaciones de beneficio. Por su parte, las empresas de menor tamaño buscaron establecer contratos con las «nuevas» beneficiadoras, con la finalidad de vender sus productos a un mejor precio o bajar el gasto de sus ensayes, según el caso. Además los gambusinos o pequeños mineros vendieron su mineral a las plantas de beneficio, enriqueciendo los porcentajes de producción de éstas ${ }^{79}$. La compañía $S a n R a-$ fael, por ejemplo, adquirió desde su Hacienda de beneficio, la mayor parte

75 Southworth, 1905: 134.

76 Ruiz de la Barrera, 1995: 42.

77 Ver: Oviedo Gámez, 1993: 176-189.

78 Southworth, 1905: 136.

79 Uribe Salas, 1999: 296-302. 
del mineral que producía la compañía Santa Ana por medio de diversos convenios ${ }^{80}$.

El crecimiento de las compañías permitió que las transacciones comerciales y de compra-venta de minas se efectuaran cada vez más entre los mineros locales, que compraban, vendían o arrendaban las propiedades según la buena o mala suerte de sus negocios. Si en la segunda mitad del siglo XIX podemos decir que la Cía. Pachuca y Real del Monte monopolizó los contratos de arrendamiento de empresa a empresa, a finales de esa centuria, las pequeñas y medianas empresas de la región también comenzaron a refaccionar y aviar a otras negociaciones. La pequeña empresa Santa Ana y la mediana San Rafael, por ejemplo, realizaron contratos de avíos de minas entre sí y de compra-venta de minas $^{81}$. También las compañías que tenían menos recursos, por medio de contratos, permitían que una empresa con mayor capital costeara los gastos de exploración, desagüe o extracción, a cambio de acciones o mineral en bruto ${ }^{82}$.

Por otra parte la inversión estadounidense, que ya tenía tiempo materializándose en la región mediante algunas proveedoras de servicios e insumos, llegó a finales del porfiriato a la minería pachuqueña. Sin embargo la naturaleza de sus minerales, básicamente compuestos de plata y plomo, interesó en menor medida a los mineros norteamericanos, que entonces buscaban la explotación de metales industriales. Este suceso permitió que las pequeñas y medianas empresas locales aprovecharan el desinterés de los estadunidenses, para invertir dinero en la mejora de ciertas áreas de la actividad productiva y continuar extrayendo grandes cantidades de plata hasta avanzado el siglo XX.

A manera de conclusión podemos decir que ejemplos de pequeñas y medianas empresas como las negociaciones mineras San Rafael y Anexas y Santa Gertrudis, impiden realizar la generalización historiográfica que describe al periodo final del porfirismo como un proceso de especulación, abandono de minas y venta de empresas mexicanas. Para el caso del distrito de Pachuca y Real del Monte en particular, es evidente que la riqueza de las vetas, la capacidad empresarial de las compañías y las políticas públicas favorables a la minería de la plata ${ }^{83}$, dieron nuevos bríos a las empresas, aún con la depreciación de

80 AHCMRM, Fondo Compañías Filiales, Sección Santa Ana, Serie Relaciones Externas, vol. 152 , exp. 1,15 y 18.

81 AHCMRM, Fondo Compañías Filiales, Sección Santa Ana, Serie Relaciones Externas, vol. 152 , exp. 1 y 15 .

82 AHCMRM, Fondo Compañías Filiales, Sección Santa Ana, Serie Relaciones Externas, vol. 153 , exp. 27.

83 Véase la temprana legislación minera que realizó este estado, mejorando las condiciones fiscales en dicho territorio, a diferencia de lo que pasaba en el centro del país, que seguía 
este mineral. Cabe destacar que muchos mineros se vieron beneficiados con la situación internacional, al producir con sus metales moneda que en el intercambio del comercio internacional proporcionaban un valor agregado al interior.

Pero también es significativo señalar que la presencia y desempeño de las medianas y pequeñas empresas mineras durante el largo gobierno del general Porfirio Díaz se dio en un contexto de monopolio minero-metalúrgico promovido por la Compañía de Minas Pachuca y Real del Monte. En ese escenario la estrategia que implementaron las empresas mineras locales para no caer en una red de dependencia y ser absorbidas por la gran empresa minera de Real del Monte y Pachuca, tanto en su etapa mexicana como estadounidense, recayó en tres aspectos básicos: modernización del área contable, que les permitió visualizar los costos-beneficios en cada circunstancia política o económica; ampliación de los estudios de prospección geológica que aseguró el conocimiento sobre la naturaleza de las zonas mineralizadas, su potencial y ley, y facilitó la adaptación de sistemas de beneficio tradicional y moderno; y por último, la aplicación de una política de bajos salarios, como ocurrió en muchos otros centros mineros de México, que abonaría al descontento de los trabajadores.

Efectivamente, la conjugación de éstos y otros elementos aseguró la permanencia de las empresas locales en un medio altamente competitivo. Pero el aumento de la producción que se registra descansó indudablemente en la explotación de la mano de obra, que inhibió al mismo tiempo la reconversión del aparato productivo o la necesidad de inversiones fuertes en tecnología. A su vez los bajos salarios pagados a los trabajadores impactaron en los costos de producción, situación que garantizó ganancias y utilidades no despreciables a los medianos y pequeños empresarios mineros.

Por último, es interesante observar que la bonanza minera que registra la región de Pachuca y Real del Monte en el periodo de estudio, tuvo en los inversionistas locales, a través de pequeñas y medianas empresas, un elemento dinamizador de su desarrollo productivo y tejido empresarial, escasamente estudiado por los especialistas. Ciertamente se redujeron los costos de producción sobre la base de salarios bajos sin que el Estado mexicano se preocupara por ello, al menos hasta iniciar el siglo XX. Pero éste modelo de organización de la producción mostraría sus fisuras y debilidades en las décadas de 1910 y 1920; primero con el movimiento social de reivindicación contenido en los

imponiendo un código minero caduco de orden colonial, en «Código de Minería del estado de Hidalgo», 1964, vol. II: 4-32. 
programas de la Revolución Mexicana; y más tarde, con la gran depresión económica de 1929-1932 que arrastraría tras de sí a la minería tradicional mexicana, productora de metales preciosos, y con el viejo artilugio de compite reduciendo el salario.

\section{BIBLIOGRAFÍA}

Argudín, Luna, «La reforma monetaria Limanturiana», Relaciones, XVII/67-68, El Colegio de Michoacán (México, 1996): 173-201.

Bátiz Vázquez, José Antonio, «Aspectos financieros y monetarios», Ciro Cardoso (coord.), México en el siglo XIX. Historia económica y estructura social (1821-1910), México, Editorial Nueva Imagen, 1980: 167-192.

Baumhauer, Hermann, et al., Historia universal, Barcelona, Editorial Labor, 1956.

Benetti, Carlo, Moneda y teoría del valor, México, Fondo de Cultura Económica, Universidad Autónoma Metropolitana, 1990.

Bernstein, Marvin D., The Mexican Mining Industry, 1890-1950: a Study of the Interaction of Politics Economics, and Technology, New York, USA, State University, 1964.

Busto, Emiliano, «Estadística de la República mexicana, estado que guardan la agricultura, industria, minería y comercio» (anexo), Memoria de Hacienda del año económico de 1877-1878, México, 2 tomos, Imprenta de Ignacio Cumplido, 1880.

Casasús, Joaquín, La cuestión de la plata en México: el problema monetario, la depreciación de la plata y sus remedios, Historia de los impuestos sobre el oro y la plata, México, Tipografía de la oficina impresora del timbre, 1886.

Cerutti, Mario, «Natalidad empresarial en Monterrey, 1885-1930», Tercer Seminario Nacional sobre Empresas y Empresarios del centro y norte de México, siglos XIX y $X X$, Morelia, UMSNH, 2002 (ponencia), pp. 1-29.

Coatsworth, John H., Los orígenes del atraso. Nueve ensayos de historia económica de México en los siglos XVIII y XIX, México, Alianza, 1990.

«Código de Minería del estado de Hidalgo», Hidalgo, octubre de 1881, en Legislación Minera Mexicana, México, Consejo de Recursos no Renovables, V. II, 1964: 4-32.

Dahlgren, Charles Bunker, Minas históricas de la República mexicana, México, Oficina Tipográfica de la Secretaría de Fomento, 1887.

De Lucio, Felipe P., «La plata y la deuda externa», Geomimet, núm. 147 (México, mayo-junio 1987): 17-31.

Del Cueto, Héctor Hugo, Cuando el peso valía más que el dólar, ensayo histórico de las devaluaciones monetarias en México, México, Impresora Juan Pablo, 1959. 
D’Olwer, Luis Nicolau, «Las inversiones extranjeras», Daniel Cosío Villegas (coord.), Historia moderna de México. El porfiriato, vida económica, México, editorial Hermes, 1974: 972-1185.

D’Olwer, Luis Nicolau, El progreso latino, VI/1 al 24 (México, enero-junio 1907).

Busto, Emiliano, Estadística de la República mexicana, México, Imprenta de Ignacio Cumplido, T. II, 1880.

Flores Clair, Eduardo, «Minas y mineros: pago en especie y conflictos. 1790-1880», Historias, vol. 13, INAH (México, abril-junio 1986): 51-67.

García, J. Aurelio, «Reseña minera del estado de Hidalgo», Boletín Minero, vol. XIX (México, 1925): 7-56.

García Solórzano, Bulmaro, Problemas monetarios y del desarrollo económico de México, México, Avelar Hnos. impresores, 1963.

García, Trinidad, Los mineros mexicanos: colección de artículos sobre tradiciones y narraciones mineras, México, Porrúa, 1970.

González, Fernando, Alberto Grothe y Leopoldo Salazar, La industria minera de México, Cuaderno I, estado de Hidalgo, México, Imprenta y Fotocopia de la Secretaría de Fomento, 1911.

Gurza, Jaime, Apuntes sobre la cuestión de la plata en México, Durango, Imprenta de S. Dorador y Hno., 1902.

Herrera Canales, Inés, El comercio exterior de México, 1821-1875, México, El Colegio de México, 1977.

Herrera Canales, Inés, «Empresa minera y región en México. La Compañía de Minas de Real del Monte y Pachuca (1824-1906)», en Siglo XIX, IV/8, UANL (México, julio-diciembre 1989): 103-123.

Herrera Canales, Inés y Rina Ortiz, «La minería en Hidalgo. De la colonia al siglo XX», José Alfredo Uribe Salas (coord.), Recuento histórico-bibliográfico de la minería en la región central de México, Morelia, Instituto de Investigaciones Históricas, UMSNH, 1994: 19-65.

Leal, Juan Felipe, La burguesía y el Estado mexicano, México, El Caballito, 1972.

Limantour, José Ivés, Memoria de la Secretaría de Hacienda y Crédito Público, correspondiente al año económico del $1 .^{\circ}$ de julio de 1900 al 30 de junio de 1901, México, Tipografía de la Oficina Impresora de Estampillas, Palacio Nacional, 1904.

Ludlow, Leonor y Carlos Marichal (coords.), La banca en México, 1820-1920, México, Instituto Mora, Instituto de Investigaciones Históricas/UNAM, El Colegio de México, El Colegio de Michoacán, 1998.

Manzano, Teodomiro, Anales del estado de Hidalgo, 2. ${ }^{a}$ parte, 1869 a marzo de 1927, Pachuca, Gobierno del estado de Hidalgo, 1927. 
Marichal, Carlos, Las inversiones extranjeras en América Latina, México, Fondo de Cultura Económica, 1989.

Marx, Carlos, Federico Engels, Materiales para la historia de la América Latina, México, Cuadernos de Pasado y Presente, núm. 30, Siglo XXI Editores, 1980.

Mason Hart, John, El México revolucionario, México, Alianza, 1997.

McMaster, John, «Aventuras asiáticas del peso mexicano», Historia Mexicana, vol. 8, núm. 3, El Colegio de México (México, 1959): 372-399.

Memoria de Hacienda y Crédito Público, correspondiente al año fiscal de $1 .^{\circ}$ de julio de 1903 al 30 de junio de 1904, presentada por el secretario de Hacienda al Congreso de la Unión, México, Tipografía de la Impresora de Estampillas, 1909.

Meyer Cosío, Francisco Javier, La minería en Guanajuato (1892-1913), México, El Colegio de Michoacán, Universidad de Guanajuato, 1998.

Meyer, Rosa María, «Los Beistegui. Especuladores y mineros, 1830-1869», en Ciro Cardoso (coord.), Formación y desarrollo de la burguesía en México. Siglo XIX, México, Siglo XXI, 1987: 108-139.

Miranda Arrieta, Eduardo, Economía y comunicaciones en el estado de Guerrero, 1877-1910, Morelia, Instituto de Investigaciones Históricas/UMSNH, 1994.

Ortega Morel, Javier, Minería y ferrocarriles. El caso de Pachuca y Real del Monte (tesis de Maestría), México, Facultad de Filosofía y Letras, UNAM, 2000.

Nava Oteo, Guadalupe, «La minería», Daniel Cosío Villegas (coord.), Historia moderna de México. El porfiriato, vida económica, México, Hermes, 1974: 179-291.

Nava Oteo, Guadalupe, «La minería bajo el porfiriato», Ciro Cardoso (coord.), México en el siglo XIX. Historia económica y estructura social (1821-1910), México, Nueva Imagen, 1980: 339-380.

Ortiz Peralta, Rina, «Las casas de moneda provinciales en México en el siglo XIX», José Antonio Vázquez y José Enrique Covarrubias (coords.), La moneda en México, 1750-1920, México, Instituto Mora, El Colegio de México, El Colegio de Michoacán, Instituto de Investigaciones Históricas/UNAM, 1998: 131-154.

Ortiz Peralta, Rina, «El beneficio de minerales en el siglo XIX, el caso de la compañía Real del Monte y Pachuca», Tzintzun, núm. 14, IIH, UMSNH (México, julio-diciembre 1991): 72-85.

Oviedo Gámez, Belem, Guía General del Archivo Histórico de la Compañía de Minas de Real del Monte y Pachuca, México, Archivo Histórico y Museo de Minería, A. C., AGN, 1993.

Quintana, Miguel A., Los ensayos monetarios como consecuencia de la baja de la plata. El problema de la plata y el de la moneda de plata en el mundo y México, México, Imprenta Galas, 1931. 
Roeder, Ralph, Hacia el México moderno, México, Fondo de Cultura Económica, T. II, 1973.

Romero, Matías, «Memoria de Hacienda y Crédito Público correspondiente al año económico transcurrido del 1 de julio de 1870 al 30 de junio de 1871», Mac Gregor (comp.), Textos escogidos/Matías Romero, México, Consejo Nacional para la Cultura y las Artes (CNCA), 1992: 285-299.

Romero, Matías, «Entrevista con Mr. Bayard, Proyecto de convención monetaria» e «Inauguración de la conferencia internacional monetaria» (anexos), Salvador E. Morales Pérez, Entre el oro y la plata. La cuestión monetaria y el proyecto de integración panamericano, México, CIC, Ing. Jorge L. Tamayo, 1996: 135-162.

Romero Gil, Juan Manuel, «La minería en el noroeste: estancamiento y desarrollo (1870-1880)», Inés Herrera Canales (coord.), La minería mexicana. De la colonia al siglo XX, México, Instituto Mora, El Colegio de México, UNAM, 1998: 119-159.

Ruiz de la Barrera, Rocío, La empresa de minas del Real del Monte (1849-1906), Tesis doctoral, México, El Colegio de México, 1995.

Samuelson, Paul y William Nordhaus, Economía, México, trad. Luis Toharía, McGraw-Hill, 1986.

Sánchez Díaz, Gerardo, El suroeste de Michoacán: economía y sociedad 1852-1910, Morelia, Instituto de Investigaciones Históricas/UMSNH, 1988.

Sariego, José Luis et al., El Estado y la minería mexicana, política, trabajo y sociedad durante el siglo XX, México, Fondo de Cultura Económica, SEMIP, 1988.

Secretaría de Fomento, La crisis monetaria, estudios sobre la crisis mercantil y la depreciación de la plata, México, Oficina Tipográfica de la Secretaría de Fomento, 1886.

Serrano, Gustavo, La minería y su influencia en el progreso y desarrollo de México, México, UNAM, 1951.

Soto Oliver, Nicolás, La minería. El distrito minero Pachuca-Real del Monte a través de la historia, Pachuca, Gobierno del estado de Hidalgo, 1985.

Southworth, J. R., Las minas de México, Liverpool, Blake \& Mackenzie, tomo IX, 1905.

Staples, Anne, Bonanzas y borrascas mineras: El Estado de México 1821-1876, Zinacantepec, El Colegio Mexiquense, 1994.

Torres Gaytán, Ricardo, Un siglo de devaluaciones del peso mexicano, México, Siglo XXI editores, 1990.

Urías Hermosillo, Margarita, «Manuel Escandón: de las diligencias al ferrocarril: 1832-1862», Ciro Cardoso (coord.), Formación y desarrollo de la burguesía en México. Siglo XIX, México, Siglo XXI, 1987: 25-56. 
Uribe Salas, José Alfredo, «Depreciación de la plata y ciencia de los metales en la coyuntura de fin de siglo», María Teresa Cortés Zavala, Consuelo Naranjo Orovio y José Alfredo Uribe Salas (coords.), El Caribe y América Latina, el 98 en la coyuntura imperial, México, Instituto de Investigaciones Históricas/UMSNH, Gobierno del Estado de Michoacán, CISC, Universidad de Puerto Rico, 1999: 291-312.

Uribe Salas, José Alfredo, «Economía y mercado en la minería tradicional mexicana, 1873-1929», Revista de Indias, LXI/222 (España, 2001): 267-290.

Uribe Salas, José Alfredo, Minería tradicional e industrialización. Las Dos Estrellas en El Oro y Tlalpujahua: historia de una empresa minera en México, 1898-1938, Madrid, tesis doctoral, Universidad Complutense de Madrid, 1998.

Uribe Salas, José Alfredo, «El ocaso de los minerales preciosos en México», José Alfredo Uribe Salas et al., Historias y procesos. El quehacer de los historiadores en la Universidad Michoacana, Morelia, Facultad de Historia/UMSNH, 2000: 311-329.

Uribe Salas, José Alfredo, Historia de la minería en Michoacán, Morelia, Facultad de Historia/UMSNH, Sociedad Mexicana de Mineralogía, Museo Tecnológico Minas Dos Estrellas, vol. I, 2002.

Uribe Salas, José Alfredo, Michoacán en el siglo XIX. Cinco ensayos de historia económica y social, Morelia, Instituto de Investigaciones Históricas/UMSNH, 1999.

Valdés Larowsky, Vera, «México y China: del galeón de Manila al primer tratado de 1889», Estudios de historia moderna y contemporánea de México, vol. 9 (documento 107) México, Instituto de Investigaciones Históricas/UNAM, 1983: 9-19.

Velasco Ávila, Cuauhtémoc, et al., Estado y minería en México (1767-1910), México, Fondo de Cultura Económica, INAH, Comisión de Fomento Minero, 1988.

Velasco Ávila, Cuauhtémoc, et al., «Nuevo auge minero: el porfiriato», Inés Herrera Canales (coord.), La minería mexicana. De la colonia al siglo XX, México, Instituto Mora, El Colegio de México, UNAM, 1998: 160-181.

Vilar, Pierre, Oro y moneda en la historia, 1450-1920, España, Ariel, 1974.

Walter, David, Parentesco, negocios y política. La casa Martínez del Río en México, 1823-1867, México, Alianza, 1991.

Ward, Henry, México en 1827, México, Fondo de Cultura Económica, 1981.

Fecha de recepción: 19 de junio de 2010

Fecha de aceptación: 22 de septiembre de 2010 


\section{Silver depreciation, public policies and business development. Small and medium-sized Mexican mining enterprises of Pachuca and Real del Monte}

This article studies the business strategies and capacity of small and medium-sized mining enterprises that operated in the Pachuca-Real del Monte mining district in Mexico in the late $19^{\text {th }}$ century. In a regional economic context dominated by the monopoly of the Compañía de Minas Real del Monte y Pachuca, small and medium-sized enterprises managed to obtain advantages from both the silver depreciation in the international currency markets and the Mexican public policies focused precisely on mitigating the fall in the price of silver after 1873. The way that some minor and medium-sized local entrepreneurs injected new life into mining activities in the region, thereby actually benefiting from the international circumstances, is analysed. In sum, it was the small and medium-sized mining companies that supported the productive and business development that characterized the period of mining growth in the district during the dictatorship of President Porfirio Diaz.

KEY WORDS: Small and medium-sized mining companies in the Pachuca-Real del Monte district; silver depreciation; public policy; business development. 